\title{
Sasa borealis extract exerts an antidiabetic effect via activation of the AMP-activated protein kinase
}

\author{
Jung Soo Nam ${ }^{1, *}$, Hee Jin Chung ${ }^{1, *}$, Min Kyung Jang ${ }^{1}$, In Ah Jung ${ }^{2}$, Seong Ha Park ${ }^{1}$, Su In Cho ${ }^{1}$ and \\ Myeong Ho Jung ${ }^{1, \S}$ \\ ${ }^{1}$ School of Korean Medicine, Pusan National University, Beomeo-ri, Mulguem-eup, Yangsan, Gyeongnam 626-770, Korea \\ ${ }^{2}$ Langley High School, 6520 Georgetown Pike, McLean, VA 22102, USA
}

\begin{abstract}
Leaf of Sasa borealis, a species of bamboo, has been reported to exhibit anti-hyperglycemic effect. However, its antidiabetic mechanism is not fully understood. In this study, we examined whether an extract of $S$. borealis activates AMP-activated protein kinase (AMPK) and exerts anti-hyperglycemic effects. Treatment with the $S$. borealis extract increased insulin signaling and phosphorylation of AMPK and stimulated the expression of its downstream targets, including PPARa, ACO, and CPT-1 in C2C12 cells and PPARa in HepG2 cells. However, inhibition of AMPK activation attenuated insulin signaling and prevented the stimulation of AMPK target genes. The $S$. borealis extract increased glucose uptake in C2C12 cells and suppressed expression of the gluconeogenic gene, PEPCK in HepG2 cells. The extract significantly reduced blood glucose and triglyceride levels in STZ-induced diabetic mice. The extract enhanced AMPK phosphorylation and increased Glut- 4 expression in the skeletal muscle of the mice. These findings demonstrated that the $S$. borealis extract exerts its anti-hyperglycemic effect through activation of AMPK and enhancement of insulin signaling.
\end{abstract}

Key Words: Antidiabetic effect, AMP-activated protein kinase, Sasa borealis, insulin signaling

\section{Introduction}

Type 2 diabetes is characterized by decreased secretion of insulin by the pancreas and resistance to the action of insulin in various tissues (e.g., muscle, liver, and adipose), leading to impaired glucose uptake [1]. The prevalence of type 2 diabetes has increased sharply in recent decades, and has tracked with similar increases in the prevalence of obesity, one of the primary risk factors for type 2 diabetes. Controlling hyperglycemia is the most important factor for reducing the risks associated with diabetes and diabetic complications. Management of type 2 diabetes usually begins with a change of diet and exercise [2], and most patients ultimately require pharmacotherapy such as an oral antidiabetic drug (OAD) [1]. OADs include sulfonylurea, non-sulfonylurea secretagogues, biguanides, thiazolidinediones, glucosidase inhibitors, and glucagon-like peptide-1 (GLP-1) inhibitors.

Plants are abundant sources of biologically active molecules that have played a critical role in pharmacology. On the basis of the knowledge of their traditional therapeutic applications, many of these natural products have been demonstrated to have beneficial medicinal attributes [3]. The use of herbal or natural medicines for the treatment of various disorders has a long and extensive history. Various medicinal herbal products, including herbs used in Chinese medicine, have beneficial effects on diabetes and are used as non-prescription treatments for diabetes [4]. Bamboo has been used for medicinal purposes and for making tea for centuries in Korea and other Asian countries. Various beneficial effects of bamboo leaves [5-9], shoot [10], shavings [11] and oils [12] on metabolic disorders and cardiovascular disease have been reported. Sasa borealis, a species of bamboo, has been reported to exhibit anti-hyperglycemic and antidiabetic activities by increasing insulin secretion [7], improving insulin resistance via modulation of inflammatory cytokine secretion, and decreasing oxidative stress [13], as well as demonstrating anti-obesity activity [6]. Furthermore, S. borealis leaf extracts had a beneficial effect on levels of adiponectin, resistin, and related molecules which are involved in cardiovascular disease such as C-reactive protein and homocysteine [6]. Although many medicinal effects of $S$. borealis have been proposed, the exact mechanisms involved in potentiating these effects still remains unclear.

\footnotetext{
This research was supported by the Basic Science Research Program through the National Research Foundation of Korea (NRF) funded by the Ministry of Education, Science, and Technology (331-2008-1-E-00036) and was financially supported by the ${ }^{2} 2011$ Post-Doc. Development Program』of Pusan National University.

${ }^{\S}$ Corresponding Author: Myeong Ho Jung, Tel. 82-51-510-8432, Fax. 82-51-510-8437, Email. jung0603@pusan.ac.kr

* These authors contributed equally to this work.

Received: July 16, 2012, Revised: October 15, 2012, Accepted: November 8, 2012

(c)2013 The Korean Nutrition Society and the Korean Society of Community Nutrition

This is an Open Access article distributed under the terms of the Creative Commons Attribution Non-Commercial License (http://creativecommons.org/licenses/by-nc/3.0/)

which permits unrestricted non-commercial use, distribution, and reproduction in any medium, provided the original work is properly cited.
} 
Adenosine monophosphate (AMP)-activated protein kinase (AMPK), a metabolic sensor that acts as a cellular fuel gauge in eukaryotes, is a well-characterized target of antidiabetic treatments. AMPK is activated under ATP-depleting conditions such as hypoxia, ischemia, reactive oxygen species (ROS), heat shock, and glucose deprivation and it subsequently induces ATP-generation pathways for maintaining cellular homeostasis [14]. In addition to controlling energy homeostasis, AMPK enhances insulin sensitivity through increased glucose uptake and lipid oxidation in skeletal muscle and inhibition of glucose and lipid synthesis in the liver [15]. Therefore, AMPK is a key molecule in controlling metabolic diseases such as type 2 diabetes, obesity, and cancer. Discovery and development of a natural AMPK activator will provide a novel strategy for overcoming human diseases such as type 2 diabetes, obesity, and cancer.

In this study, we examined the effect of an extract of $S$. borealis on AMPK activation, insulin signaling, and glucose uptake in $\mathrm{C} 2 \mathrm{C} 12$ cells and on gluconeogenesis in HepG2 cells. Moreover, we also evaluated the hypoglycemic effect and AMPK activation in mice with streptozotocin (STZ)-induced diabetes.

\section{Materials and Methods}

\section{S. borealis and preparation of leaf extract}

$S$. borealis, which was purchased from the Kyungdong Oriental Herbal market, Korea, was identified by Prof. Su In Cho, one of the authors. A voucher specimen was deposited at the School of Korean Medicine, Pusan National University. Fresh leaves of $S$. borealis were washed thoroughly with tap water and dried at $30^{\circ} \mathrm{C}$ for $30 \mathrm{~h}$, and pulverized using a mill. Five volume of $70 \%$ methanol was added to the pulverized samples and the mixture was stirred for $24 \mathrm{~h}$. Finally, extracts were filtered through a cheese cloth, concentrated by using a vacuum batch evaporator (Best Korea Co.), and freeze-dried with a lyophilizer (SFDTS 10K, Samwon Freezing Engineering Co., Korea). The yield was $9.5 \% \mathrm{w} / \mathrm{w}$ dry matter.

\section{Cell culture and treatment}

The HepG2 hepatocytes and C2C12 skeletal myoblasts were obtained from the American Type Culture Collection (ATCC, USA). The HepG2 cells were cultured in Dulbecco's modified Eagle's medium (DMEM) containing glucose (Invitrogen, USA), supplemented with $10 \%(\mathrm{v} / \mathrm{v})$ fetal bovine serum (Gibco BRL, USA). The $\mathrm{C}_{2} \mathrm{C}_{12}$ skeletal myoblasts were grown in DMEM supplemented with $2 \%$ horse serum to induce differentiation into myotubes. To investigate the effect of the $S$. borealis extract on AMPK activation or expression of AMPK target genes, HepG2 and $\mathrm{C} 2 \mathrm{C} 12$ cells were treated with $40 \mu \mathrm{g} / \mathrm{mL}$ of the extract for $24 \mathrm{~h}$. To see the effects of $S$. borealis extract on insulin signaling,
HepG2 or C2C12 cells were treated with $40 \mu \mathrm{g} / \mathrm{ml}$ of the extract for $24 \mathrm{~h}$, and then incubated with $100 \mathrm{nM}$ insulin for $1 \mathrm{~h}$. Compound C-treated cells were preincubated with $10 \mu \mathrm{M}$ of compound $\mathrm{C}$ or vehicle (DMSO) with the extract. Compound $\mathrm{C}$ was purchased from Calbiochem (La Jolla, CA, USA)

\section{Western blot analysis}

Total protein was extracted from cells with the PRO-PREP reagent (iNtRON Biotechnology, Korea), resolved by sodium dodecyl sulfate-polyacrylamide gel electrophoresis (SDS-PAGE), and immunoblotted with antibodies against AMPK and the phosphorylated form of AMPK (pAMPK), insulin receptor substrate-1 (pIRS-1), and Akt (pAkt) (Santa Cruz Biotechnology, USA). The immune complexes were visualized with an enhanced chemiluminescence detection system (Amersham Biosciences, Sweden) according to the manufacturer's instructions, in conjunction with ImageQuant LAS 4000 luminescent image analyzer (GE Healthcare, USA).

\section{Reverse transcription-polymerase chain reaction (RT-PCR)}

Total RNA was extracted from cells using the TRIzol lysis reagent (Invitrogen). The mRNA in the samples was reversetranscribed using the SuperscriptII ${ }^{\mathrm{TM}}$ First Strand Kit (Invitrogen). The resulting cDNA was amplified by PCR using primer pairs specific for peroxisome proliferator-associated receptor a (PPAR a), F (5'-CGTCCTGGCCTTCTAAACGTAG-3') and R (5'-CCT GTAGATCTC CTGCAGTAGCG-3'), acetyl-CoA oxidase (ACO), F (5'-TCAAGCCAGGTGAACCAGAA-3') and R (5'-TGCCTA TGCCTTCCAGTTTG-3'), and carnitine palmitoyltransferase-1 (CPT-1), F (5'-AATCCGAACATTCCGTACCC-3') and R (5'GCAAATCTTCTGGCAAACGA-3'). The housekeeping gene, Actin, was amplified using the sense primer 5'-GCCCTGAGG CACTCTTCCA-3' and the antisense primer 5'-GAAGGTAGT TTCGTGGATGCC A-3'.

\section{Measurement of glucose uptake}

Glucose uptake assays were performed using the glucose analog 2-[N-(7-nitrobenz-2-oxa-1,3-diazol-4-yl) amino]-2-deoxyd-glucose (2-NBDG; Invitrogen), a fluorescent indicator for direct glucose uptake. Differentiated $\mathrm{C} 2 \mathrm{C} 12$ cells were treated with vehicle or extract $(40 \mu \mathrm{g} / \mathrm{ml})$ and $1 \mu \mathrm{M}$ insulin in the presence or absence of $10 \mu \mathrm{M} 2-\mathrm{NBDG}$ for $1 \mathrm{~h}$. The fluorescence intensity of 2-NBDG was recorded using a FACS flow cytometer (FACSCanto $^{\mathrm{TM}}$ II Flow Cytometry System : BD Biosciences, USA). To rule out false-positives, the fluorescence intensity of cells treated with extract in the absence of 2-NBDG was measured and this value was considered as the background level. The relative fluorescence intensities, minus the background level, were used for data analysis. 


\section{Measurement of gluconeogenic gene expression}

HepG2 cells were treated with $40 \mu \mathrm{g} / \mathrm{ml}$ of the $S$. borealis extract for $24 \mathrm{~h}$, washed 3 times with pre-warmed DMEM, and then stimulated by cAMP $(100 \mu \mathrm{M}) /$ dexamethasone $(500 \mathrm{nM})$ in the presence of $40 \mu \mathrm{g} / \mathrm{ml}$ of the extract for $24 \mathrm{~h}$. Total RNA was prepared from the cells and RT-PCR was performed using phosphoenolpyruvate carboxykinase (PEPCK)-specific primers.

\section{Animal studies}

ICR mice aged 8 weeks were purchased from the Oriental Bio (Daejeon, Korea) and housed individually in polycarbonate cages under a 12-h light-dark cycle at $21-23{ }^{\circ} \mathrm{C}$ and $40-60 \%$ humidity. The hyperglycemia was induced by intraperitoneal injection of streptozotocin (STZ) $(100 \mathrm{mg} / \mathrm{kg}$ body weight) in citrate buffer ( $\mathrm{pH} 4.5$ ) after $12 \mathrm{~h}$ fasting for $7 \mathrm{~d}$, and the body weight and fasting blood glucose level of STZ-treated mice were measured. The mice with the fasting glucose levels above $200 \mathrm{mg} / \mathrm{dL}$ were considered hyperglycemia and included in this study. On the basis of the fasting glucose levels, the mice were divided into 3 groups ( $\mathrm{n}=7$, each); (1) diabetic control (treated with STZ alone), (2) low-dose treatment (treated with STZ $+300 \mathrm{mg} / \mathrm{kg}$ body weight $S$. borealis extract), (3) high-dose treatment (treated with STZ $+500 \mathrm{mg} / \mathrm{kg}$ body weigh $S$. borealis extract). All groups were fed a standard AIN-76 semi-synthetic diet (American Institute of Nutrition, USA), and experimental groups were administered $300 \mathrm{mg} / \mathrm{kg}$ or $500 \mathrm{mg} / \mathrm{kg}$ of the extract orally for 2 weeks. After starvation for $12 \mathrm{~h}$, the mice were anesthetized with ether and blood samples were collected from the inferior vena cava for measuring blood biomarkers. All animal procedures were in accordance with the Pusan National University guidelines for the care and use of laboratory animals.

\section{Fasting blood glucose and biomarker analyses}

The fasting blood glucose concentration was measured by using a Glucometer (GlucoDr, Allmedicus, Korea) with venous blood drawn from the mouse tail vein after a $12 \mathrm{~h}$ fast. Blood samples were centrifuged at $1,000 \times \mathrm{g}$ for $15 \mathrm{~min}$ at $4{ }^{\circ} \mathrm{C}$ for biochemical analysis. The insulin level was measured with an enzyme-linked immunosorbent assay (ELISA) kit (ALPCO Diagnostics, USA). The lipids such as total cholesterol and triglycerides were determined with commercial kits (SigmaAldrich, USA), while the plasma free fatty acid (FFA) concentration was determined with an acyl-CoA synthetase (ACS)ascorbate oxidase (ACOD) method (Wako Pure Chemical Industries, Japan).

\section{Statistical analysis}

All data are presented as the means $\pm \mathrm{SE}$. The data were evaluated by one-way ANOVA and the differences between means were determined using Duncan's multiple-range test. Values were considered statistically significant at $P<0.05$.

\section{Results}

$S$. borealis extract augments insulin signaling in C2C12 and HepG2 cells

We first examined the cytotoxicity of $S$. borealis extracts with three different concentractions $(10,20,40 \mu \mathrm{g} / \mathrm{ml})$ on $\mathrm{C} 2 \mathrm{C} 12$ and HepG2 cells. As shown in Fig. 1, the extracts had little influence on the viability of both cells. Next, we investigated the effect of the $40 \mu \mathrm{g} / \mathrm{ml}$ of $S$. borealis extract on insulin action in insulin-sensitive cells. After $\mathrm{C} 2 \mathrm{C} 12$ and HepG2 cells were treated with the extract for $24 \mathrm{~h}$ and incubated with insulin for $1 \mathrm{~h}$, the insulin-stimulated phosphorylation of IRS-1 and Akt was evaluated. Insulin stimulated tyrosine phosphorylation of IRS-1, and cotreatment with the extract significantly increased the level of phosphorylated IRS-1 (Fig. 2) in both cells. Similarly, serine phosphorylation of Akt also increased significantly with the extract (data not shown), suggesting that the extract augmented insulin signaling.
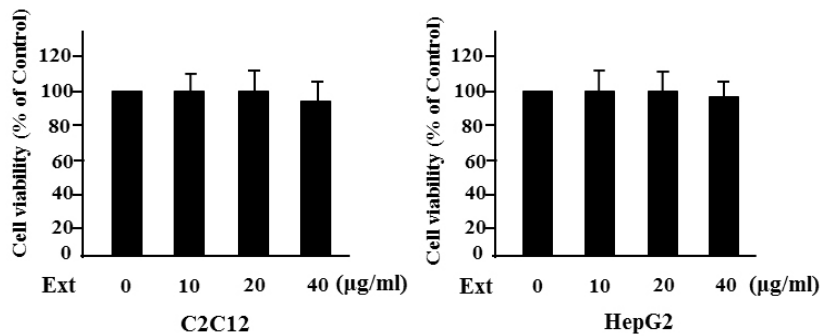

Fig. 1. Cytotoxicity of Sasa borealis extracts. C2C12 or HepG2 cells were treated with three different concentractions of the extract (Ext) $(10,20,40 \mu \mathrm{g} / \mathrm{ml})$ for 24 h. Cell cytotoxicity was measured by MTT assay.
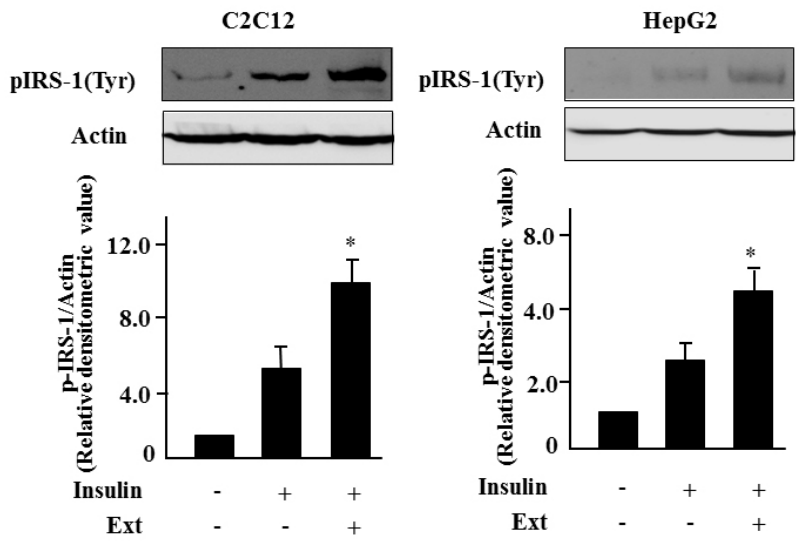

Fig. 2. Sasa borealis extract augments insulin signaling in $\mathrm{C} 2 \mathrm{C} 12$ and $\mathrm{HepG} 2$ cells. C2C12 or HepG2 cells were treated with the extract (Ext) $(40 \mu \mathrm{g} / \mathrm{ml})$ for $24 \mathrm{~h}$ and then incubated with insulin $(100 \mathrm{nM})$ for $1 \mathrm{~h}$. Levels of phosphorylated IRS-1 (pIRS-1) was evaluated by western blotting. All experiments were performed three times, and representative figures are shown. The bars represent the relative densitometric values compared to untreated samples. The values are expressed as the mean $\pm \mathrm{SE}\left({ }^{*} P<0.05\right)$. 


\section{S. borealis extract activates AMPK}

It has been reported that AMPK is an attractive therapeutic target for the treatment of type 2 diabetes and obesity [15]. Therefore, we next investigated the effect of the extract on AMPK activation. To this end, $\mathrm{C} 2 \mathrm{C} 12$ and HepG2 cells were
(A)

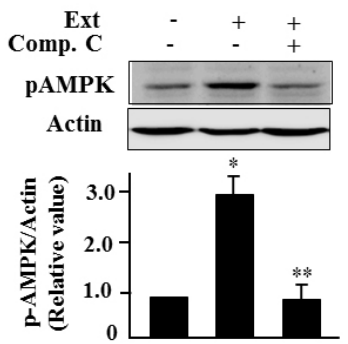

(B)

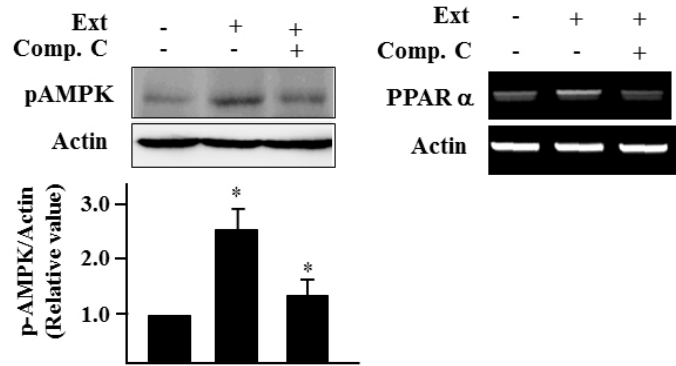

Fig. 3. Sasa borealis extract activates AMPK in $\mathrm{C} 2 \mathrm{C} 12$ and HepG2 cells. (A) C2C12 cells were treated with the extract $(40 \mu \mathrm{g} / \mathrm{ml})$ for $24 \mathrm{~h}$ in the absence or presence of compound C (10 $\mu \mathrm{M})$ (Comp.C). Phosphorylated AMPK (pAMPK) was assessed by western blotting. The expression of AMPK target genes was evaluated by RT-PCR using gene specific primers. (B) HepG2 cells were treated with the extract $(40 \mu \mathrm{g} / \mathrm{ml})$ for $24 \mathrm{~h}$ in the absence or presence of compound $\mathrm{C}(10 \mu \mathrm{M})$. Levels of pAMPK were assessed by western blotting. The expression of AMPK target genes was assessed by RT-PCR, Actin was used as the internal control. All experiments were performed three times, and representative figures are shown. The bars represent the relative densitometric values compared to untreated samples. The values are expressed as the mean \pm SE $\left({ }^{*} P<0.05 ;{ }^{* *} P<0.01\right)$.
$\mathrm{C} 2 \mathrm{C} 12$

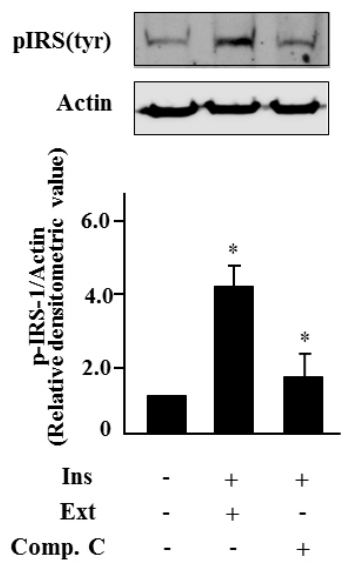

HepG2

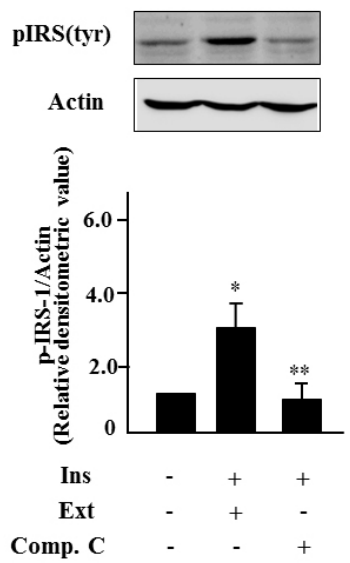

Fig. 4. Sasa borealis extract activates insulin signaling through AMPK activation. C2C12 cells or HepG2 cells were treated with the extract $(40 \mu \mathrm{g} / \mathrm{ml})$ for $24 \mathrm{~h}$ in the absence or presence of compound $\mathrm{C}(10 \mu \mathrm{M})$ and incubated with insulin for $1 \mathrm{~h}$, Level of plRS-1 was assessed by western blotting. All experiments were performed three times, and representative figures are shown. The bars represent the relative densitometric values compared to untreated samples. The values are expressed as the mean $\pm \mathrm{SE}\left({ }^{\star} P<0.05,{ }^{*} P<0.01\right)$. incubated with the extract for $24 \mathrm{~h}$ and the pAMPK levels and expression of its target genes were determined by western blotting and RT-PCR, respectively. Treatment with the extract increased pAMPK levels in $\mathrm{C} 2 \mathrm{C} 12$ cells, whereas treatment with compound $\mathrm{C}$, an inhibitor of AMPK, blocked the increase in pAMPK levels (Fig. 3A). Consistent with the increase in pAMPK levels, treatment with the extract stimulated the expression of AMPK target genes, including PPARa, ACO and CPT-1 in $\mathrm{C} 2 \mathrm{C} 12$ cells (Fig. 3A). Treatment with the extract increased the pAMPK and PPARa expression in HepG2 cells as well (Fig. 3B). These results demonstrated that the extract activates AMPK in skeletal muscle and liver cells.

To investigate the ability of the $S$. borealis extract to activate insulin signaling through AMPK activation, we assessed the phosphorylated forms of IRS-1 in $\mathrm{C} 2 \mathrm{C} 12$ cells and HepG2 cells pretreated with compound C. Co-incubation of cells with the extract and insulin stimulated phosphorylation of IRS-1. However, pretreatment with compound $\mathrm{C}$ blocked the increase in pIRS-1 (Fig. 4), suggesting that the $S$. borealis extract activates insulin signaling through AMPK activation.

\section{S. borealis extract enhances glucose uptake in $C 2 C 12$ cells and suppresses PEPCK gene expression in HepG2 cells}

AMPK activation increases insulin-mediated glucose uptake in skeletal muscle cells. Furthermore, AMPK is known to suppress the gene expression of gluconeogenic genes, including glucose6-phosphatase (G-6-Pase) and phosphoenolpyruvate (PEPCK), and inhibit hepatic glucose production [15]. Therefore, we measured insulin-stimulated glucose uptake in $\mathrm{C} 2 \mathrm{C} 12$ cell treated with the extract. A fluorescent indicator of direct glucose uptake, 2-NBDG, was used in the glucose uptake assay. Insulin or the extract stimulated 2-NBDG uptake in $\mathrm{C} 2 \mathrm{C} 12$ cells (Fig. 5A). Co-treatment of the cells with the extract increased the insulin-stimulated 2-NBDG uptake in $\mathrm{C} 2 \mathrm{C} 12$ cells. Then, we
(A)

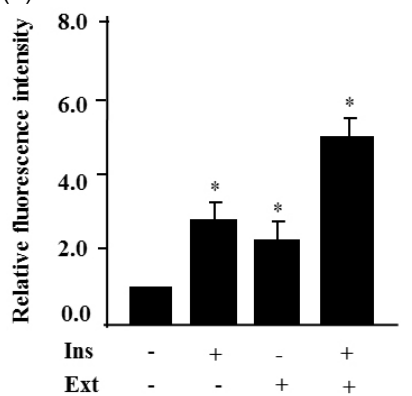

(B)

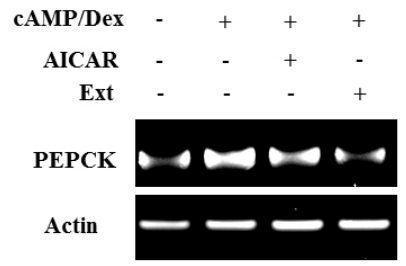

Fig. 5. Sasa borealis extract enhances glucose uptake in $\mathrm{C} 2 \mathrm{C} 12$ cells and suppresses PEPCK gene expression in HepG2. (A) C2C12 cells were treated with the extract $(40 \mu \mathrm{g} / \mathrm{ml})$ and incubated with insulin for $1 \mathrm{~h}$, and insulin-stimulated 2-NBDG uptake was measured. The relative fluorescence intensities, minus the background levels, were used for statistical analyses. The values are expressed as the mean \pm SE and were determined from 3 independent experiments ( ${ }^{*} P<0.05$ ). (B) HepG2 cells were treated with the extract (40 $\mu \mathrm{g} / \mathrm{ml})$ for $24 \mathrm{~h}$ in the absence or presence of cAMP/dexamethasone (Dex). PEPCK expression was evaluated by RT-PCR. Actin was used as the internal control. 
examined the effect of the $S$. borealis extract on gluconeogenic gene expression in HepG2 cells. Dexamethasone and cAMP increased the expression of PEPCK, but the extract efficiently prevented the increase in PEPCK gene expression (Fig. 5B).

\section{S. borealis extract decreases blood glucose and triglyceride levels in mice with STZ-induced diabetes}

To examine the in vivo antidiabetic effects of the $S$. borealis extract on diabetes, STZ-induced diabetes were treated orally with 2 different concentrations of the extract $(300$ and $500 \mathrm{mg} / \mathrm{kg}$ body weight) every day for 2 weeks (from 10 to 12 weeks of age). Compared to untreated normal mice, STZ-treated mice showed a marked increase in blood glucose levels and a significant decrease in blood insulin levels. Administration of the extract did not have any significant effect on their body weight or food intake (data not shown). However, treatment with 500 $\mathrm{mg} / \mathrm{kg}$ of the extract led to a significant reduction in the fasting
(A)

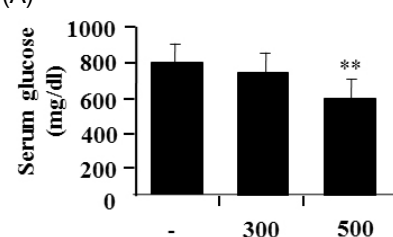

(C)

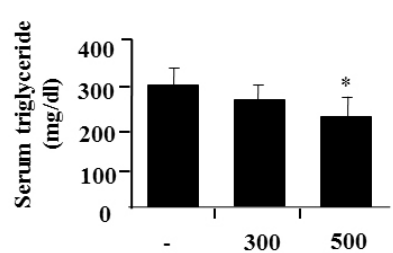

(B)

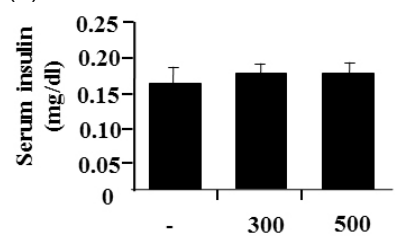

(D)

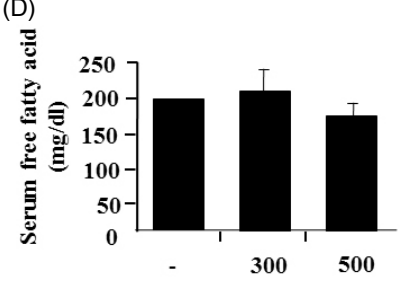

Fig. 6. Sasa borealis extract decreases blood glucose and triglyceride levels in mice with STZ-induced diabetes. The extracts (300 and $500 \mathrm{mg} / \mathrm{kg}$ body weight) were administrated daily to STZ-mice for 2 weeks. The blood glucose levels from fasting mice were determined on the indicated day. Values are the mean \pm SE $(n=7)\left({ }^{*} P<0.05 ;{ }^{* *} P<0.001\right)$.

(A)

STZ

$\mathrm{STZ}+500$

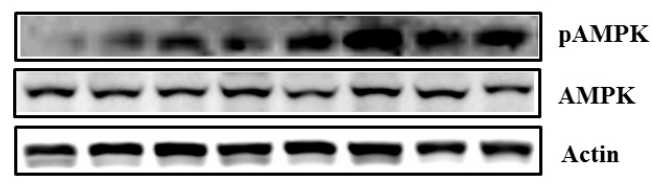

(B)

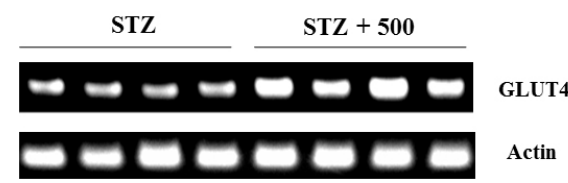

Fig. 7. Sasa borealis extract increased AMPK phosphorylation and Glut4 expression in skeletal muscle of STZ-mice. (A) Lysates of soleus skeletal muscles were prepared from mice treated with STZ alone (STZ) or with STZ and extract $(500 \mathrm{mg} / \mathrm{kg})(\mathrm{STZ}+500)$ and were subjected to western blotting using an antibody specific for pAMPK. (B) Total RNA was prepared from soleus skeletal muscles of STZ-treated mice and subjected to RT-PCR using Glut4-specific primers. blood glucose level (Fig. 6A), whereas the extract did not affect the blood insulin level (Fig. 6B). Next, the effects of the extract on plasma levels of triglycerides, free fatty acid, and total cholesterol were investigated. In particular, treatment with 500 $\mathrm{mg} / \mathrm{kg}$ of the extract led to a significant decrease in plasma triglyceride levels (Fig. 6C), but not free fatty acid levels (Fig. 6D). Total cholesterol was decreased slightly at $500 \mathrm{mg} / \mathrm{kg}$ of the extract, but not statistically (data not shown).

We also determined the effect of the $S$. borealis extract on AMPK activation in vivo. To this end, we measured the pAMPK levels in soleus skeletal muscle of the STZ-mice treated with the extract. Treatment with $500 \mathrm{mg} / \mathrm{kg}$ of extract increased pAMPK levels in the skeletal muscle of STZ-mice treated with the extract, compared with non-treated STZ-mice (Fig. 7A). Consistent with the increase in pAMPK levels, $500 \mathrm{mg} / \mathrm{kg}$ of extract also increased the expression of the Glut4 gene in skeletal muscle (Fig. 7B).

\section{Discussion}

Several in vitro and animal studies have reported that bamboo extract has beneficial effects in controlling serum glucose levels [6,7]. Among all bamboos, one species of bamboo, S. borealis, has been reported to exert anti-hyperglycemic antidiabetic, and antiobesity activity. Furthermore, S. borealis leaf extracts have a beneficial effect on many proteins involved in cardiovascular disease [7]. S. borealis prevented chronic hyperglycemia-induced oxidative stress and apoptosis in human umbilical endothelial cells [16]. In this study, we characterized a new molecular target of the antidiabetic activity of $S$. borealis. We observed that the $S$. borealis extract activates AMPK in both skeletal muscle and liver cells and increases insulin sensitivity, leading to enhancement of glucose uptake in skeletal muscle and suppression of gluconeogenesis in the liver.

AMPK is a cellular energy sensor that inhibits ATP-consumption and stimulates ATP production under energy-depleted conditions. The kinase activity of AMPK is induced by a high AMP/ATP ratio. AMP binds to the 8 -subunit of AMPK and induces a conformational change that allows Thr172 of the a -subunit to be phosphorylated by AMPK kinases [14]. AMPK is activated by upstream kinases, including liver kinase B1 (LKB1) [17] and calmodulin-dependent protein kinase kinase (CaMKK) [18]. Activation of AMPK has been shown to suppress gluconeogenic gene expression and inhibit hepatic glucose production [15]. Furthermore, AMPK activation stimulates glucose uptake by increasing Glut4 translocation to the cell surface and increasing Glut4 gene expression in skeletal muscle [15]. We showed here that a $S$. borealis extract increases the phosphorylation of AMPK and stimulates the expression of AMPK target genes in both skeletal muscle and liver cells, indicating that $S$. borealis activates AMPK. Several reports suggest that activation of AMPK enhances insulin sensitivity and increases glucose 
uptake in vitro and in vivo [15]. Therefore, we investigated whether AMPK activation is involved in $S$. borealis extractstimulated insulin signaling. Treatment with $S$. borealis further increased insulin-stimulated pIRS- 1 and pAkt levels. However, blocking AMPK activation by treatment with compound $\mathrm{C}$ prevented the increase in pIRS-1 and pAkt, suggesting that activation of AMPK by $S$. borealis enhances insulin sensitivity in both skeletal muscle and liver cells. We also monitored the glucose uptake in $\mathrm{C} 2 \mathrm{C} 12$ cells. Treatment with the extract enhanced the insulin-stimulated glucose uptake in $\mathrm{C} 2 \mathrm{C} 12$ cells. AMPK activation also suppresses gluconeogenesis in the liver through inhibition of gluconeogenic genes such as PEPCK and G-6-Pase. In the current study, treatment with the extract suppressed dexamethasone/cAMP-induced PEPCK gene expression in HepG2 cells. Then, we confirmed the hypoglycemic effect of $S$. borealis and AMPK activation in STZ-induced diabetic mice. Treatment with the extract efficiently reduced blood glucose levels and increased pAMPK levels in skeletal muscle tissue. Taken together, these results demonstrated that $S$. borealis activates AMPK and increases insulin sensitivity, which lead to increased glucose uptake. Furthermore, AMPK activation by $S$. borealis decreased PEPCK gene expression, which may be involved in the reduction of blood glucose levels. Cellular glucose uptake is regulated by both insulin-dependent PI3K/Akt signaling and insulin-independent AMPK signaling [19]. The current study demonstrated that the $S$. borealis extract enhances insulin signaling, and that AMPK activation is necessary for the extract-enhanced insulin signaling. Therefore, the increase in glucose uptake by treatment with the $S$. borealis extract may be due to AMPK activation itself, as well as AMPK-enhanced insulin signaling.

A previous study reported various pharmacological components of bamboo leaf extracts, including flavones, glycosides, phenolic acids, coumarone lactones, anthraquinones, and amino acids, which have been utilized as therapeutic agents [20]. $S$. borealis leaf extracts have high levels of polyphenols and flavonoids, and the major phenolic compounds identified in the extracts included protocatechuic acid, p-hydroxybenzoic acid, caffeic acid, syringic acid, p-coumaric acid, leuteolin-6-glucoside, and tricine-7-glucoside. Triterpenoids present in $S$. borealis, friedelin and glutiol, were reported to have a potential to inhibit fat deposition [7]. Many kinds of triterpenoids extracted from several important Chinese herbal drugs such as Panax ginseng and bamboo shavings are being studied increasingly and their physiological activities and medicinal values have been the focus of recent investigations [11]. Triterpenoids extracted from the roots of Rosa rugosa have anti-inflammatory potential [21]. Furthermore, isoorientin, a flavonoidal glycoside, and its derivative were found in $S$. borealis [22]. These components have free radical scavenging activity and strong cytoprotective effects against tert-butyl hydroperoxide-induced oxidative stress in HepG2 cells [10]. In addition, a flavonoidal glycoside-containing $S$. borealis leaf extract has been reported to have a potential insulin-sensitizing activity [23]. However, the exact component involved in the antidiabetic effect of $S$. borealis has not been characterized yet. Therefore, further studies are required to identify and characterize the phytochemical component which contributes to AMPK activation and to delineate the molecular mechanism of $S$. borealis-mediated AMPK activation.

In summary, $S$. borealis exerts an anti-hyperglycemic activity through AMPK activation and increases insulin sensitivity, which, in turn, enhances glucose uptake and suppresses gluconeogenesis, resulting in the reduction of blood glucose levels.

\section{References}

1. Cheng AY, Fantus IG. Oral antihyperglycemic therapy for type 2 diabetes mellitus. CMAJ 2005;172:213-26.

2. Colberg SR, Zarrabi L, Bennington L, Nakave A, Thomas Somma C, Swain DP, Sechrist SR. Postprandial walking is better for lowering the glycemic effect of dinner than pre-dinner exercise in type 2 diabetic individuals. J Am Med Dir Assoc 2009; 10:394-7.

3. Yin J, Zhang H, Ye J. Traditional Chinese medicine in treatment of metabolic syndrome. Endocr Metab Immune Disord Drug Targets 2008;8:99-111.

4. Bailey CJ, Day C. Traditional plant medicines as treatments for diabetes. Diabetes Care 1989;12:553-64.

5. Lu B, Wu X, Shi J, Dong Y, Zhang Y. Toxicology and safety of antioxidant of bamboo leaves. Part 2: developmental toxicity test in rats with antioxidant of bamboo leaves. Food Chem Toxicol 2006;44:1739-43.

6. Kim EY, Jung EY, Lim HS, Heo YR. The effects of the Sasa borealis leaves extract on plasma adiponectin, resistin, C-reactive protein and homocysteine levels in high fat diet-induced obese C57/BL6J mice. Korean J Nutr 2007;40:303-11.

7. Ko BS, Jun DW, Jang JS, Kim JH, Park S. Effect of Sasa borealis and white lotus roots and leaves on insulin action and secretion in vitro. Korean J Food Sci Technol 2006;38:114-20.

8. Choi YJ, Choi JS, Shin SY, Bae JY, Kang SW, Kang IJ, Kang YH. Blockade of chronic high glucose-induced endothelial apoptosis by Sasa borealis bamboo extract. Exp Biol Med 2008:233:580-91.

9. Hwang JY, Han JS. Inhibitory effects of Sasa borealis leaves extracts on carbohydrate digestive enzymes and postprandial hyperglycemia. J Korean Soc Food Sci Nutr 2007;36:989-94.

10. Park EJ, Jhon DY. The antioxidant, angiotensin converting enzyme inhibition activity, and phenolic compounds of bamboo shoot extracts. Lebenson Wiss Technol 2010;43:655-9.

11. Zhang Y, Yao X, Bao B, Zhang Y. Anti-fatigue activity of a triterpenoid-rich extract from Chinese bamboo shavings (Caulis bamfusae in taeniam). Phytother Res 2006;20:872-6.

12. Choi DB, Cho KA, Na MS, Choi HS, Kim YO, Lim DH, Cho $\mathrm{SJ}$, Cho H. Effect of bamboo oil on antioxidative activity and nitrite scavenging activity. J Ind Eng Chem 2008;14:765-70.

13. Yang JH, Lim HS, Heo YR. Sasa borealis leaves extract improves insulin resistance by modulating inflammatory cytokine secretion in high fat diet-induced obese C57/BL6J mice. Nutr Res Pract 2010;4:99-105.

14. Carling D. The AMP-activated protein kinase cascade--a unifying 
system for energy control. Trends Biochem Sci 2004;29:18-24.

15. Hardie DG. Role of AMP-activated protein kinase in the metabolic syndrome and in heart disease. FEBS Lett 2008;582: 81-9.

16. Lee MJ, Park WH, Song YS, Lee YW, Song YO, Moon GS. Effect of bamboo culm extract on oxidative stress and genetic expression: bamboo culm extract ameliorates cell adhesion molecule expression and $\mathrm{NF} \kappa \mathrm{B}$ activity through the suppression of the oxidative stress. Clin Nutr 2008;27:755-63.

17. Shaw RJ, Kosmatka M, Bardeesy N, Hurley RL, Witters LA, DePinho RA, Cantley LC. The tumor suppressor LKB1 kinase directly activates AMP-activated kinase and regulates apoptosis in response to energy stress. Proc Natl Acad Sci U S A 2004; 101:3329-35.

18. Hurley RL, Anderson KA, Franzone JM, Kemp BE, Means AR, Witters LA. The Ca2+/calmodulin-dependent protein kinase kinases are AMP-activated protein kinase kinases. J Biol Chem
2005;280:29060-6.

19. Cartee GD, Wojtaszewski JF. Role of Akt substrate of $160 \mathrm{kDa}$ in insulin-stimulated and contraction-stimulated glucose transport. Appl Physiol Nutr Metab 2007;32:557-66.

20. Watson RR. Bamboo extract in the prevention of diabetes and breast cancer. In: Panee J, editor. Complementary and Alternative Therapies and the Aging Population: An Evidence-Based Approach. San Diego: Elsevier; 2009. p.159-77.

21. Jung HJ, Nam JH, Choi J, Lee KT, Park HJ. 19a-hydroxyursane-type triterpenoids: antinociceptive anti-inflammatory principles of the roots of Rosa rugosa. Biol Pharm Bull 2005;28:101-4.

22. Park HS, Lim JH, Kim HJ, Choi HJ, Lee IS. Antioxidant flavone glycosides from the leaves of Sasa borealis. Arch Pharm Res 2007;30:161-6

23. Mahato SB, Nandy AK, Roy G. Triterpenoids. Phytochemistry 1992;31:2199-249. 